University of Nebraska - Lincoln

DigitalCommons@University of Nebraska - Lincoln

Faculty Publications, Department of Child, Youth, and Family Studies

Child, Youth, and Family Studies, Department of

$6-2012$

\title{
Stress, Coping and Suicide Ideation in Chinese College Students
}

\author{
Xiaoyun Zhang \\ University of Nebraska-Lincoln, s-xzhang11@unl.edu \\ Haiping Wang \\ University of Nebraska-Lincoln \\ Yan Ruth Xia \\ University of Nebraska-Lincoln, rxia2@unl.edu \\ Xiaohong Liu \\ Guangzhou University of Chinese Medicine \\ Eunju Jung \\ University of Connecticut, eunju.jung@uconn.edu
}

Follow this and additional works at: https://digitalcommons.unl.edu/famconfacpub

Part of the Community Health Commons, Psychiatric and Mental Health Commons, and the Psychiatry and Psychology Commons

Zhang, Xiaoyun; Wang, Haiping; Xia, Yan Ruth; Liu, Xiaohong; and Jung, Eunju, "Stress, Coping and Suicide Ideation in Chinese College Students" (2012). Faculty Publications, Department of Child, Youth, and Family Studies. 79.

https://digitalcommons.unl.edu/famconfacpub/79

This Article is brought to you for free and open access by the Child, Youth, and Family Studies, Department of at DigitalCommons@University of Nebraska - Lincoln. It has been accepted for inclusion in Faculty Publications, Department of Child, Youth, and Family Studies by an authorized administrator of DigitalCommons@University of Nebraska - Lincoln. 
Published in Journal of Adolescence 35:3 (June 2012), pp. 683-690; doi:10.1016/j.adolescence.2011.10.003

Copyright ( 2011 The Foundation for Professionals in Services for Adolescents. Published by Elsevier Ltd. Used by permission.

\title{
Stress, Coping, and Suicide Ideation in Chinese College Students
}

\author{
Xiaoyun Zhang, ${ }^{1}$ Haiping Wang, ${ }^{1}$ Yan Xia, ${ }^{1}$ Xiaohong Liu, ${ }^{2}$ and Eunju Jung ${ }^{3}$ \\ 1. University of Nebraska-Lincoln, United States \\ 2. Guangzhou University of Chinese Medicine, PR China \\ 3. University of Connecticut, United States \\ Corresponding author - X. Zhang, Department of Child, Youth, and Family Studies, University of Nebraska-Lincoln, \\ 31331 Mound Rd. Apt. H, Warren, MI 48092, USA; tel 586 879-5053, email xzhang@huskers.unl.edu
}

\begin{abstract}
The study was to examine 1) whether stress and coping styles could significantly predict the probability of suicide ideation; 2) and whether coping styles were mediators or moderators on the association between life stress and suicide ideation. The survey was conducted in a sample of 671 Chinese college students. Approximately twenty percent students reported having suicide ideation. Life stress, active coping styles, and passive coping styles all had independent effect on the probability of suicide ideation. Passive coping styles, especially fantasizing, mediated the relation between life stress and suicide ideation. Moderation hypotheses were not supported. Implications of the findings and future directions were discussed.
\end{abstract}

Keywords: stress, coping, suicide ideation, mediator, moderator

\section{Introduction}

Suicide is the leading cause of death among 15-34 year olds in China, accounting for 19\% of the deaths in this age group (Phillips, Li, \& Zhang, 2002). Although the suicide rate among Chinese college students is not reported, a considerable number of suicide cases among this population have (Fan, 2006; Mooney, 2005). Suicide behavior has been conceptualized as a continuum from suicide ideation, to suicide attempt, to completed suicide (Lewinsohn et al., 1995). Suicide ideation is defined as thoughts of harming or killing oneself (Institute of Medicine, 2002). It is not only an important predictor of the suicide attempt and completed suicide but also a significant marker for other mental health problems among youth (see Thompson et al., in press). Thus, it is imperative to identify the characteristics of suicide ideation with the aim of developing effective prevention and intervention programs. The present study was aimed at investigating risk and protective factors of suicide ideation using a sample of Chinese college students.

The relationship between stress and suicide behaviors has been well-documented (e.g., Grover et al., 2009; Thompson et al., in press; Dixon et al., 1991). For example, Thompson et al. (in press) found that recent stressful life events, especially physical and psychological abuse, significantly predicted suicide ideation in youth, even after controlling for a host of other risk factors, including psychological distress. Compared to non-suicidal youth, suicidal psychiatric inpatients reported more stressful life events (Josepho and Plutchik, 1994; Wilson et al., 1995). The association between life stress and suicide risk has also been found in population-based college students (Dixon et al., 1991; Uğurlu and Ona, 2009).

Coping, as another important predictor, has also been extensively researched in understanding suicide behaviors (Wilson et al., 1995; see Speckens \& Hawton, 2005, for a review). The strain theory of suicide argues that deficient coping, which is one of the most important sources of strain, may lead to suicidal behaviors (Zhang, Wieczorek, 
Conwell, \& Tu, 2011). Empirical evidences show that adult inpatients at risk of suicide reported less use of problem solving skills than non-suicidal patients (Josepho and Plutchik, 1994; Pollock and Williams, 1998). Speckens and Hawton (2005) conducted a systematic review of international research literature on problem solving and suicidal behavior in adolescents. They concluded that adolescents who had attempted suicide were deficient in problem solving skills when compared to non-suicidal psychiatric patients or normal controls. However, this association appears to be stronger in clinical samples than in nonclinical samples (Speckens \& Hawton, 2005). Furthermore, Wilson et al. (1995) found that although suicidal adolescents had no significant differences in generating adaptive coping strategies when compared with non-suicidal adolescents, they used fewer of these generated strategies than non-suicidal control subjects did. In addition, adolescents with suicide attempts were more likely to generate maladaptive coping strategies than were non-suicidal and normal controls, including more focus on emotions, poorer cognitive orientation, and behavioral avoidance (Sadowski and Kelley, 1993; Wilson et al., 1995). Some studies of college students also found that coping had a direct effect on suicide (Blankstein et al., 2007; Dixon et al., 1991; Uğurlu and Ona, 2009). For example, some researchers have found that avoidance coping is positively associated with suicide ideation (Blankstein et al., 2007). While researchers have conducted many studies of suicide attempts among psychiatric patients, fewer studies have investigated the relationship between coping and suicide ideation among the college student population.

Coping has a direct effect on suicide behaviors; it can also be viewed as a moderating and/or medicating mechanism between life stress and suicide behaviors. Currently, researchers focus on testing psychopathological factors, including depression (Yang \& Clum, 1994), hopelessness (Dixon, Rumford, Heppner, \& Lips, 1992), and psychological distress (Thompson et al., in press), as mediators between life stress and suicide ideation. Fewer studies have tested coping as a mediator between life stress and suicide ideation. Some studies tested coping as a moderator on the relationship between stress and suicide ideation (e.g., Clum and Febbraro, 1994; Dixon et al., 1991). However, the results were inconsistent. For example, while Dixon et al. (1991) did not find the moderating effect of problem solving in a sample of college students, some studies found a significant moderating effect of problem solving on the relationships between stressful life events and suicide ideation (psychiatric adolescent inpatients in Grover et al., 2009; international students from Asia in Yang \& Clum, 1994). The results in another study also indicated the significant interaction effect between stress and perceived problem solving skills, but the effect was small (Clum \& Febbraro, 1994). To gain a clearer understanding of the role of coping between stress and suicide behaviors, the present study sought to explore both the moderating and mediating effects of coping between life stress and suicide ideation.

Compared with research in Western countries, the number of studies on Chinese youth suicide behaviors and related risk factors is limited. Several studies investigated the risk factors of suicide among youth who completed suicide. The research was mostly conducted by Zhang and his colleagues (Zhang et al., 2011, 2006, 2011) and Phillips and his colleagues (Li et al., 2008; Phillips et al., 2002). Severe life events, chronic stress, interpersonal conflict, and lack of positive coping skills were all identified in their studies. Other studies were conducted among population-based youth. Negative life events, especially academic stress and family conflicts, were a significant risk factor for suicide attempters (Liu et al., 2008; Liu and Tein, 2005).

Current research targeted on Chinese samples published in international journals focuses more on suicidal behaviors in rural youth (Zhang et al., 2010), especially rural young women (Zhang, 2010), and middle and high school students (Cui, Cheng, Xu, Chen, \& Wang, 2011). Much less high-quality research targeted at Chinese college students has been reported. Also, no studies have been conducted on coping as a moderator and mediator in the relationship between life stress and suicide ideation.

The purpose of the present study was to investigate 1) whether life stress is a significant predictor of suicide ideation; 2) whether coping is a significant predictor of suicide ideation; and 3) whether coping is a mediator or moderator in the relationship between life stress and suicide ideation. Specifically, we expected that higher levels of life stress and more use of passive coping predicted a higher probability of suicide ideation, while more use of active coping predicted lower probability of suicide ideation. We did not have specific hypotheses for coping as a mediator or moderator due to the dearth of related literature and the inconsistent results in previous studies.

\section{Method}

\section{Recruitment, procedure, and sample}

This present study used the secondary survey data which had been collected by other Chinese colleagues from a comprehensive public university in South China in 2006. The survey was a part of the university effort to increase the understanding of the suicide, stress, and coping, in order to enhance suicide prevention. The students were invited to voluntarily participate in an online survey through email. The survey was confidential and no identification information was linked to individual data. In the recruiting email, potential risks (e.g., temporary upset arising from questions about suicide behaviors), confidentiality, and procedures were explained prior to the participation. The survey link led participants to the secured survey website developed by the University Mental Health Center. By logging on the survey site and completing the survey, students gave their consent to participation. Students could freely withdraw at anytime of answering the online survey questions.

This was a convenient sample. Total 790 invitation emails were sent out and the valid surveys were 689 . The response rate was $87 \%$. Eighteen cases aged older than 25 were excluded in the present analysis due to the age. Total 671 participants were included and male participants were $326(48.6 \%)$. They were between the ages of 19 and 
25 years $(M=21.8, S D=1.65)$. There were freshman $(N=158,23.5 \%)$, sophomore $(N=189,28.2 \%)$, junior $(N=125$, $18.6 \%)$, senior $(N=100,14.9 \%)$, and first-year graduate students $(N=99,14.8 \%)$ respectively. Twenty three percent of students were the only child in the family. Students left home at average $16.9(S D=5.2)$ years old. About four percent of them reported their parents $(N=29)$ were divorced. Around 21 percent students reported that their fathers' educational levels were elementary school or middle school, 32 percent of them were high school or technique school, and around 36 percent of them were college, university or above the level. Around 41 percent students reported that their mothers' educational levels were elementary school or middle school, around 32 percent of them were in high school or technique school, and 24 percent of them were college, university or above level. Before going to college, 43 percent $(N=288)$ participants lived in rural area and 48 percent $(N=322)$ in urban area respectively.

\section{Measures}

Coping was assessed by the Coping Style Questionnaire (CSQ; Xiao \& Xu, 1996), which was developed by the Chinese scholars based on the coping inventories widely used in Western countries (e.g., Folkman and Lazarus, 1988; Stone and Neale, 1984). The items were created considering Chinese culture and language system. CSQ has accepted reliability and validity and has been widely used in coping research in Chinese college students (Cao et al., 2009; Xiao and Li, 1996; Xiao and Xu, 1996). The CSQ consisted of 62 items assessing 6 categories of coping efforts, including problem solving (e.g., "I try my best to change the situation and make it better."), seeking help (e.g., "I will ask someone's help to deal with the difficulties."), rationalization (e.g., "when having conflict with someone, it is due to his or her bad personality."), avoidance (e.g., "I do not think much about the situation which makes me upset"), fantasizing (e.g., "I often fantasize I am a superman and can deal with all the difficulties"), and self-blaming (e.g., "I often blame myself."). The participants were asked whether or not they used the coping (No $=0$ ), and If Yes, to rate on a 3-digit scale of the usefulness of this coping effort (not $=1$, a little $=2$, very $=3$ ). Thus, each item was scored from 0 to 3 . The total scores of each subscale were calculated. In addition, the total scores of problem solving and seeking help were summed to compose of the subscale of adaptive coping. The total scores of self-blaming, avoidance, and fantasizing were summed to compose of passive coping style. The Cronbach's alphas of the six subscales were .73 (problem solving, 12 items), .63 (seeking help, 10 items), .66 (rationalizing, 11 items), .72 (avoidance, 10 items), .73 (fantasizing, 10 items), and .77 (self-blaming, 9 items). The Cronbach's alphas of active coping style and passive coping style subscale were .79 and .87 , respectively.

Life stress was measured using Adolescent Self-Rating Life Events Checklist (ASLEC, Liu, Liu, Yang, \& Zhao, 1997). The ASLEC has accepted reliability and validity and has been successfully used in Chinese adolescents and young adults (Liu et al., 2000, 1997; Qiu and Yan, 2009). It consists of 6 subscales with total 26 items. The participants were asked whether or not the event happened in their life during the past 12 months $(\mathrm{No}=0)$, and if Yes, to rate on a 5 -digit scale of the stressfulness of this event (not stressful $=1$ to extremely stressful $=5$ ). Thus, each item was scored from 0 to 5 . The total score of each subscale was calculated. The subscales were interpersonal relationship stress (6 items, e.g., "misunderstood or blamed wrongly by others"), school stress (5 items, e.g., "failing on exam or not getting the expected scores"), death and loss (3 items, e.g., "a relative or friend died"), physical health (3 items, e.g., "I got a severe illness"), setbacks (7 items, e.g., "I was fined.") and others (2 items). The Cronbach's alpha for these subscales are .79 (interpersonal relationship), .72 (school stress), .70 (death and loss), .86 (setbacks), .57 (physical health), and .52 (others), indicating an acceptable internal consistency of these measures. The overall stress was used in the analysis.

Suicide ideation was measured by one statement, "Have you thought about committing suicide?" There were five options, ranged from "Never $=1$ " to "Always $=5$ ".

Other controlled demographic variables included gender, age, if having siblings, and residence (rural or urban area). They were controlled in each model.

\section{Data analysis}

\section{Logistic regression analysis}

Suicide ideation was recoded as 0 (never $=1)$ and 1 ( $2=$ once in a while to $5=$ always). Life stress, active coping, and passive coping were all recoded into three levels (mean, one SD below, and one SD above), respectively. We tested if the overall stress, active coping and passive coping could significantly predict suicide ideation, after controlling for gender, age, if only child, and residence.

\section{Moderation analyses}

Active coping and passive coping were tested together as moderators of the relation between stress and suicide ideation using hierarchal linear regression analysis. In the first step, the predictor variables and control variables were entered into the model. In the second step, the interaction terms of life stress $\times$ active coping and life stress $\times$ passive coping were entered into the model. Mean-centered life stress and coping were used, in order to reduce collinearity between the interaction and main effect (Aiken \& West, 1991). Missing data were dealt with listwise deletion.

\section{Mediation analyses}

We tested different coping styles as multiple mediators simultaneously in one single model. Preacher and Hayes (2008) listed four advantages of specifying and testing a single multiple mediation model, instead of separate simple 
mediation models. First, it can determine whether an overall mediating effect of a set of variables exists, which can help researchers to conclude whether the set of variables mediates the effect of the independent variable on the dependent variable. Second, we can know the magnitude of one specific mediating effect, conditional on the presence of other mediators in the model. Third, the involvement of multiple mediators in one model can reduce the likelihood of parameter bias due to potential omitted variables. Fourth, it allows the researcher to contrast and determine the relative magnitude of each specific mediating effect.

Bootstrapping approach is suggested to assess whether the total and specific mediating effects were significant (Preacher \& Hayes, 2008). The advantage of this approach is that multivariate normality of the sampling distributions of the total and specific mediating effects, which is rare in the real world, does not need to be assumed (Preacher \& Hayes, 2008). To bootstrap the sampling distribution of the specific and total mediating effects, a sample size of $n$ cases is replaced for the original sample. Using the new sample, the path coefficients will be re-estimated and the mediating effects can be calculated (Preacher \& Hayes, 2008). In the present analysis, we repeated the process for 5000 times. Thus, 5000 estimates of the total and specific mediating effects were attained. The distributions of these 5000 estimates serve as empirical, nonparametric approximations of the sampling distributions of the total and specific mediating effects. The ninety-five percent bootstrap Confidence Intervals (CIs) of the total and mediating effects were reported. SPSS Macro Indirect software developed by Preacher and Hayes (2008) was used to conduct the analysis. It can be downloaded from http://www.fhayes.com/spss-sas-and-mplus-macros-and-code.html. Missing data were dealt with listwise deletion.

\section{Results}

\section{Means, standard deviation and correlation}

Approximately twenty percent students $(N=137)$ reported having suicide ideation, of whom around four percent $(N=5)$ students reported thinking of suicide often or always. Means, standard deviations and correlation coefficients among life stress, coping styles, and suicide ideation were seen in Table 1. As expected, suicide ideation was positively related to life stress and passive coping style and the three subscales of passive coping: self-blame, fantasizing, and avoidance. It was negatively associated with active coping style and the two subscales of active coping: problem solving and seeking help. Life stress was significantly positively related to passive coping and the three subscales of passive coping, while no significant correlations were found between life stress and active coping style and between life stress and the two subscales of active coping, respectively.

\section{Logistic regression analysis}

After controlling for gender, age, only child or not, and residence, life stress, active coping and passive coping significantly predict suicide ideation. The Odds Ratios (OR) were 2.02, .59, and 2.34, respectively. For example, when the life stress increased from mean to one standard deviation above the mean, the degree of suicide ideation would increase as twice as the degree of suicide ideation when life stress was at mean level. When the level of passive coping style increases from average to one standard deviation above, the degree of suicide ideation would also increase as about twice as the degree of suicide ideation when passive coping was at mean level. However, when active coping increased from mean to one standard deviation above, the degree of suicide ideation would decrease as close to half as the degree of suicide ideation when active coping was at mean level. The results were seen in Table 2.

\section{Mediation analyses}

First, active coping style and passive coping style were tested as multiple mediators for the relation between life stress and suicide ideation. The results showed that total mediating effect of active coping and passive coping was significant, and it was .0016, and 95\% bootstrap CI [.0006, .0031]. The specific mediating effect of passive coping was significant. The effect was .0019, and 95\% bootstrap CI [.0010 to .0035]. The specific mediating effect of active coping was at a significant trend. The effect was -.0003 , and $95 \%$ bootstrap CI $[-.0009,0]$. The mediating effect of passive

Table 1. Mean, standard deviation, and correlation matrix.

\begin{tabular}{|c|c|c|c|c|c|c|c|c|c|}
\hline & $M(S D)$ & Stress & $\begin{array}{l}\text { Active } \\
\text { coping }\end{array}$ & $\begin{array}{l}\text { Passive } \\
\text { coping }\end{array}$ & Self-Blame & Avoidance & Fantasizing & $\begin{array}{l}\text { Problem } \\
\text { solving }\end{array}$ & $\begin{array}{l}\text { Seeking } \\
\text { help }\end{array}$ \\
\hline Suicide ideation & $1.25(.55)$ & $.13^{* *}$ & $-.10^{* *}$ & $.23^{* * *}$ & $.20^{* * *}$ & $.18^{* * *}$ & $.22^{* * *}$ & $-.10^{*}$ & $-.08^{*}$ \\
\hline Stress & $29.30(17.84)$ & & .07 & $.25^{* * *}$ & $.22^{* * *}$ & $.19^{* * *}$ & $.23^{* * *}$ & .05 & .07 \\
\hline Active coping & $29.07(9.94)$ & & & $.23^{* * *}$ & $.13^{* *}$ & $.24^{* * *}$ & $.24^{* * *}$ & $.91^{* * *}$ & $.83^{* * *}$ \\
\hline Passive coping & $22.61(12.98)$ & & & & $.87^{* * *}$ & $.84^{* * *}$ & $.89 * * *$ & $.23^{* * *}$ & $.18^{* * *}$ \\
\hline Self-blame & $6.18(4.96)$ & & & & & $.59^{* * *}$ & $.68^{* * *}$ & .06 & $.19^{* * *}$ \\
\hline Avoidance & $8.27(4.73)$ & & & & & & $.63^{* * *}$ & $.21^{* * *}$ & $.20^{* * *}$ \\
\hline Fantasizing & $8.16(5.25)$ & & & & & & & $.21^{* * *}$ & $.21^{* * *}$ \\
\hline Problem solving & $18.17(6.44)$ & & & & & & & & $.52^{* * *}$ \\
\hline Seeking help & $10.91(4.92)$ & & & & & & & & \\
\hline
\end{tabular}


Table 2. The logistic regression analysis of life stress, passive coping, and active coping on suicide ideation.

\begin{tabular}{lcccr}
\hline & \multicolumn{1}{l}{} & S. E. & Wald & OR \\
\hline Life stress & $.70^{* *}$ & .21 & 11.67 & 2.02 \\
Passive coping & $.85^{* * *}$ & .23 & 13.34 & 2.34 \\
Active coping & $-.52^{*}$ & .19 & 7.838 & .59 \\
\hline
\end{tabular}

${ }^{*} p<.05 ;{ }^{* *} p<.01 ;{ }^{* * *} p<.001$

coping was significantly greater than that of active coping. Active coping effect was -.0023 lower than passive coping, and $95 \%$ bootstrap CI [-.0040, -.0012]. The model with unstandardized path coefficients was seen in Figure 1.

Secondly, we tested each subscales of passive coping as multiple mediators of the relation between stress and suicide ideation. The results showed that only fantasizing was a significant mediator. The mediating effect of fantasizing was .0012, and 95\% bootstrap CI [.0005, .0023]. The mediating effect of self-blaming was not significant, 95\% bootstrap CI $[-.0007, .0010]$. The mediating effect of avoidance was not significant, either, 95\% bootstrap CI [-.0003, .0012]. The model with unstandardized path coefficients was seen in Figure 2.

Thirdly, we tested the subscales of active coping as multiple mediators of the relation between life stress and suicide ideation. The specific mediating effect of seeking help and problem solving were both not significant, with $95 \%$ bootstrap CI [-.0006, .0001] and [-.0006, .0001], respectively.

\section{Moderation analyses}

The interaction term between life stress and active coping did not significantly predict suicide ideation, $\beta=.03$, $t=.63, p>.05$. Also, the interaction term between life stress and passive coping was not significant of predicting suicide ideation, either, $\beta=.02, t=.37, p>.05$.

\section{Discussion}

In our sample, we found that the prevalence rate of suicide ideation was close to 20 percent, which is close to the rates found in previous studies (Zhang and Jin, 1996; Zhang et al., 1999). It also fell in the range of 6\%-39.2\% reported in college students in other countries (Arria et al., 2009; Garlow et al., 2008; Mackenzie et al., 2011; Roh et al., 2007; Toprak et al., 2011). Because our sample came from only one university, generalizing the rate and comparing it with the findings of previous studies is difficult. A survey with a nationally representative sample of college students should be conducted.

One purpose of the present study was to examine whether life stress was significantly associated with suicide ideation. The finding that life stress significantly predicted the risk of suicide is consistent with previous findings in research targeted at Western (e.g., Thompson et al., in press; Uğurlu and Ona, 2009) and Chinese adolescents and young adults (e.g., Liu and Tein, 2005; Zhang et al., 2011). Life stress was an independent and unique predictor even after controlling for coping styles, which was also consistent with previous studies on college students (Dixon et al., 1991).

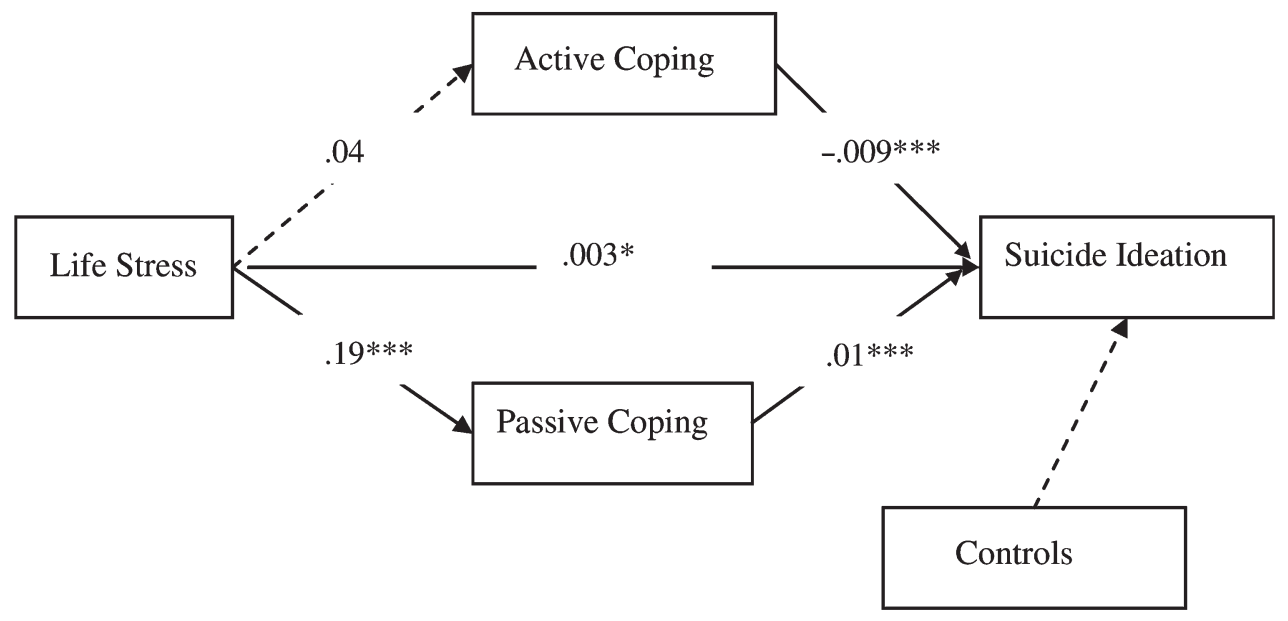

Figure 1. The mediating model of passive coping and active coping between life stress and suicide ideation.

$$
{ }^{*} p<.05 ;{ }^{* *} p<.01 ;{ }^{* * *} p<.001
$$




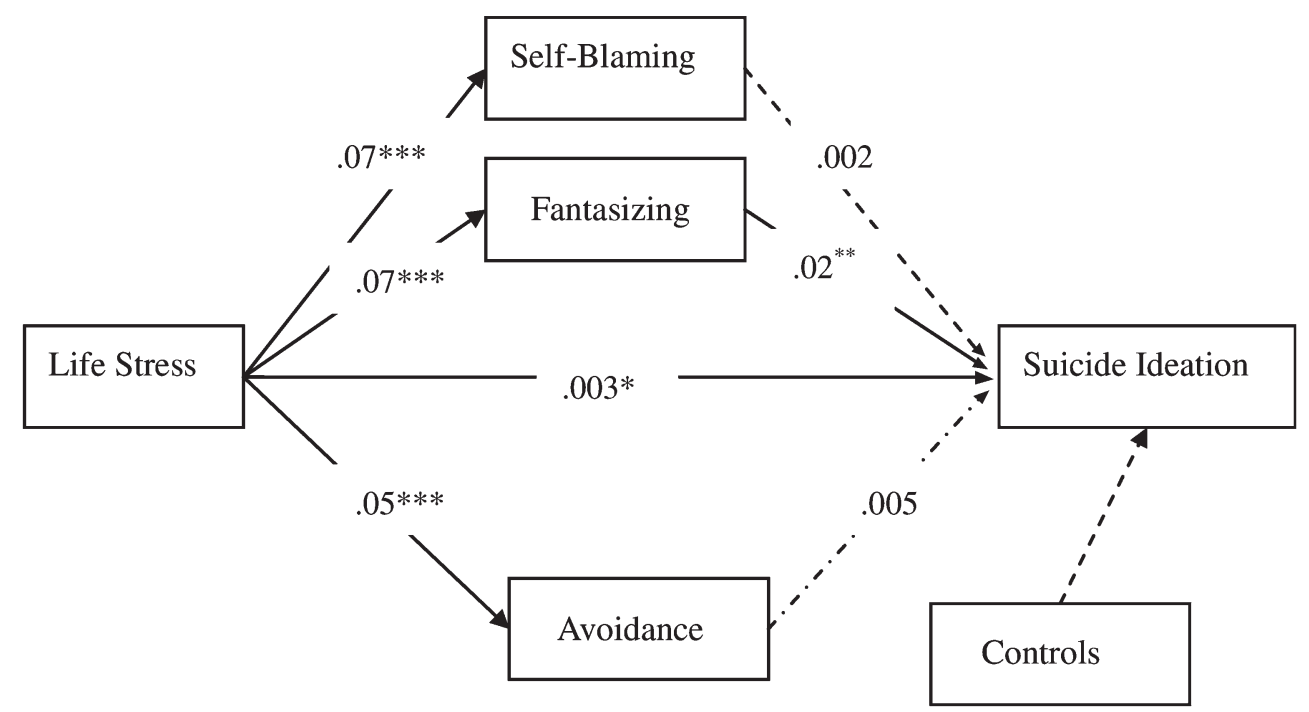

Figure 2. The mediating model of self-blaming, fantasizing, and avoidance between life stress and suicide ideation. ${ }^{*} p<.05 ;{ }^{* *} p<.01 ;{ }^{* * *} p<.001$

Some researchers have found common biological evidence between adverse life stress and suicidality (Sunnqvist, Westrin, \& Träskman-Bendz, 2008). Thus, adverse life stress is a consistent and strong predictor in suicide behaviors. In China, college students are faced with a variety of sources of stress, including living far from home, a crowded living space, and strict regulations (Mooney, 2005), as well as parents' high academic expectations (Schneider \& Lee, 1990). Furthermore, rapid social and economic changes also cause significant levels of stress for today's youth, for example, the fast pace of life, the unrealisticly high price of housing, high unemployment, relatively low wages after graduation, and social unfairness. This means that a good education may not necessarily lead to a good living. Thus, all these stressors can be a cumulative risk for suicidal behaviors in college students. Researchers can investigate the effect of stress on suicide ideation from social ecological perspectives.

Consistent with previous studies on both Western and Chinese adolescents (e.g., Dixon et al., 1991; Lai Kwok and Shek, 2009), an active coping style was negatively associated with suicide ideation in the results of the current study. A lack of effective coping skills has been found in suicide victims (Zhang et al., 2010), suicidal inpatients (Wilson et al., 1995) and population-based adolescents and young adults with suicide ideation (Lai Kwok \& Shek, 2009). A passive coping style was found to be positively associated with suicide ideation in the present study. It is consistent with previous studies that suicidal youths reported more maladaptive coping strategies than non-suicidal controls (Gould et al., 2004; Wilson et al., 1995). Many Chinese children today are the only child in the home and are treated as "little emperors." They are overprotected by their parents. They are often ill-prepared to deal with stressful demands on university campuses when they go to college (Mooney, 2005). Thus, the suicide risk would be increased in these younger generations (see Mooney, 2005).

Another purpose of the present study was to examine the mediating and moderating role of coping style between life stress and suicide ideation. The results showed that the mediating role of active coping was significant at trend, and passive coping was a significant mediator between life stress and suicide ideation. Higher life stress increased use of passive coping, in turn, passive coping increased suicide ideation. Especially, fantasizing was a stronger mediator. It is understandable that students with fantasizing coping style may fantasize about the problems disappearing after committing suicide. The other mediators, avoidance and self-blame, were not significant. It might be due to the collinearity problem caused by high correlations among different passive coping styles (.59-.68).

Unlike some previous studies (e.g., Clum and Febbraro, 1994; Grover et al., 2009; Yang and Clum, 1994), the hypotheses of the moderating roles of active coping and passive coping were not supported. According to the definitions of mediator and moderator, moderators are those preexisting and relatively stable characteristics of an individual that increase or decrease the effect of stress on psychological outcomes, while mediators represent the mechanisms that stress affects (Grant et al., 2003; Wadsworth et al., 2005). Researchers suggest that coping serves as a mediator in children and adolescents and as a moderator in adults, because coping is less stable in childhood and adolescence than in adulthood (Wadsworth et al., 2004, 2005). The results in the present study may indicate that college students' coping is still developing and less stable, as children, early and middle adolescents do. As mentioned before, Chinese college students are usually overprotected by their parents, and it is always the first time for them to leave home when they go to college. They may begin to learn to cope in the real world during the college period. Thus, coping may serve as a mediator between life stress and suicide ideation. 
There are limitations in this study. First, it was a cross-sectional design, thus the directionality of the relationships among life stress, coping and suicide ideation was not determined. Second, stress, coping and suicide ideation were all measured by students' self-reports, which may lead to shared method variance problems (Compas, Connor-Smith, Saltzman, Thomsen, \& Wadsworth, 2001). The association between life stress, coping and suicide ideation could be spurious. In future studies, researchers can gather information from different sources, e.g., parents, siblings or peers. Third, suicide ideation was measured using one statement on a 5-point scale. It is better to use a suicide ideation scale with sound reliability and validity information (e.g., Watson, Goldney, Fisher, \& Merritt, 2001). Finally, the sample was limited to one university. The interpretation of the findings has to be cautious for generalization.

Although the present study has these limitations, it has contributed to the current literature of the stress-coping framework in understanding suicidal behaviors using a Chinese sample. One of the contributions was produced by testing different coping styles as multiple mediators in one single model. To our knowledge, no researchers have tested coping styles using a multiple mediator model before. Furthermore, we also tested the moderating roles of active coping and passive coping styles in one single model, in order to compare with the mediation analysis. Finally, the mediation findings have implications for suicide prevention and intervention. Practitioners can develop program curricula aimed at reducing suicide ideation in college students by increasing the repertoires of adaptive coping strategies and decreasing their passive coping styles, especially the fantasizing coping style.

\section{References}

Aiken, L. S., \& West, S. G. (1991). Multiple regression: Testing and interpreting interactions. Newbury Park, CA: Sage.

Arria, A. M., O'Grady, K. E., Caldeira, K. M., Vincent, K. B., Wilcox, H. C., \& Wish, E. D. (2009). Suicide ideation among college students: a multivariate analysis. Archives of Suicide Research, 13(3), 230-246. doi:10.1080/13811110903044351.

Blankstein, K. R., Lumley, C. H., \& Crawford, A. (2007). Perfectionism, hopelessness, and suicide ideation: revisions to diathesisstress and specific vulnerability models. Journal of Rational-Emotive $\mathcal{E}$ Cognitive-Behavior Therapy, 25(4), 279-319. doi:10.1007/ s10942-007-0053-6.

Cao, H., Cao, P., \& Wang, P. (2009). A correlation study on coping styles and social anxiety in college students. Journal of Electronic Science and Technology (Social Science Edition), 11(3), 91-95.

Clum, G. A., \& Febbraro, G. A. R. (1994). Stress, social support, and problem-solving appraisal/skills: prediction of suicide severity within a college sample. Journal of Psychopathology and Behavioral Assessment, 16(1), 69-83. doi:10.1007/BF02229066.

Compas, B. E., Connor-Smith, J. K., Saltzman, H., Thomsen, A. H., \& Wadsworth, M. E. (2001). Coping with stress during childhood and adolescence: problems, progress, and potential in theory and research. Psychological Bulletin, 127(1), 87-127. doi:10.1037/0033-2909.127.1.87.

Cui, S., Cheng, Y., Xu, Z., Chen, D., \& Wang, Y. (2011). Peer relationships and suicide ideation and attempts among Chinese adolescents. Child: Care, Health, and Development, 37(5), 692-702. doi:10.1111/j.1365-2214.2010.01181.x.

Dixon,W. A., Heppner, P. P., \& Anderson,W. P. (1991). Problem-solving appraisal, stress, hopelessness, and suicide ideation in a college population. Journal of Counseling Psychology, 38(1), 51-56. doi:10.1037/0022-0167.38.1.51.

Dixon, W. A., Rumford, K. G., Heppner, P. P., \& Lips, B. J. (1992). Use of different sources of stress to predict hopelessness and suicide ideation in a college population. Journal of Counseling Psychology, 39(3), 342-349. doi:10.1037/0022-0167.39.3.342.

Fan, B. (July 26, 2006). Tragedies of suicide on campus: An investigation of college students' mental health. Retrieved on August 2, 2007 from http://www.rfa.org/english/news/social/2006/08/18/china_youth/

Folkman, S., \& Lazarus, R. S. (1988). Ways of coping questionnaire: Research edition. Palo Alto, CA: Consulting Psychologists Press.

Garlow, S. J., Rosenberg, J., Moore, J. D., Haas, A. P., Koestner, B., Hendin, H., et al. (2008). Depression, desperation, and suicidal ideation in college students: results from the American foundation for suicide prevention college screening project at Emory university. Depression and Anxiety, 25, 482-488. doi:10. 1002/da.20321.

Gould, M. S., Velting, D., Kleinman, M., Lucas, C., Thomas, J. G., \& Chung, M. (2004). Teenagers' attitudes about coping strategies and help-seeking behavior for suicidality. Journal of American Academy of Child \& Adolescent Psychiatry, 43(9), 1124-1133. doi:10.1097/01.chi.0000132811.06547.31.

Grant, K. E., Compas, B. E., Stuhlmacher, A. F., Thurm, A. E., McMahon, S. D., \& Halpert, J. A. (2003). Stressors and child and adolescent psychopathology: moving from markers to mechanisms of risk. Psychological Bulletin, 129(3), 447-466. doi:10.1037/0033-2909.129.3.447.

Grover, K. E., Green, K. L., Pettit, J.W., Monteith, L. L., Garza, M. J., \& Venta, A. (2009). Journal of Clinical Psychology, 65(12), 12811290. doi:10.1002/jclp.20632.

Institute of Medicine. (2002). Reducing suicide: A national imperative. Washington, DC: The National Academies Press.

Josepho, S. A., \& Plutchik, R. (1994). Stress, coping and suicide risk in psychiatric inpatients. Suicide and Life-Threatening Behavior, 24(1), 48-57. doi:10.1111/j. 1943-278X.1994.tb00662.x.

Lai Kwok, S. Y. C., \& Shek, D. T. L. (2009). Social problems solving, family functioning, and suicidal ideation among Chinese adolescents in Hong Kong. Adolescence, 44(174), 391-406.

Lewinsohn, P. M., Langhinrichsen-Rohling, J., Langford, R., Rohde, P., Seeley, J. R., \& Chapman, J. (1995). The life attitudes schedule: a scale to assess adolescent life-enhancing and life-threatening behaviors. Suicide and Life-Threatening Behavior, 25, 458-474. doi:10.1111/j.1943-278X.1995.tb00239.x.

Li, X. Y., Phillips, M. R., Zhang, Y. P., Xu, D., \& Yang, G. H. (2008). Risk factors for suicide in China's youth: a case-control study. Psychological Medicine, 38, 397- 406. doi:10.1017/s0033291707001407.

Liu, X., \& Tein, J.-Y. (2005). Life events, psychopathology, and suicidal behavior in Chinese adolescents. Journal of Affective Disorders, 86, 195-203. doi:10.1016/ j.jad.2005.01.016.

Liu, X. C., Kurita, H., Uchiyama, M., Okawa, M., Liu, L., \& Ma, D. (2000). Life events, locus of control, and behavioral problems among Chinese adolescents. Journal of Clinical Psychology, 56(2), 1565-1577. 
Liu, X. C., Liu, L. Q., Yang, J., \& Zhao, G. F. (1997). Reliability and validity of the adolescents self-rating life events checklist. Chinese Journal of Clinical Psychology, 5, 34-36.

Liu, X. C., Oda, S., Peng, X., \& Asai, K. (1997). Life events and anxiety in Chinese medical students. Social Psychiatry and Psychiatric Epidemiology, 32(2), 63-67. doi:10.1007/BF00788922.

Liu, X., Sun, Z., \& Yang, Y. (2008). Parent-reported suicidal behaviors and correlates among adolescents in China. Journal of Affective Disorders, 105, 73-80. doi:10.1016/j.jad.2007.04.012.

Mackenzie, S., Wiegel, J. R., Mundt, M., Brown, D., Saewyc, E., Heiligenstein, E., et al. (2011). Depression and suicide ideation among students accessing campus health care. American Journal of Orthopsychiratry, 81(1), 101-107. doi:10.1111/j.1939-0025.2010.01077.

Mooney, P. (Nov, 2005). Campus life proves difficult for China's little emperors. The Chronicle of Higher Education. Oct. 03. 2011; retrieved from http://www.pjmooney.com/en/Most_Recent_Articles/Entries/2005/11/25_Campus_Life_Proves_Difficult for Chinas Little Emperors.html

Phillips, M. R., Li, X., \& Zhang, Y. (2002). Suicide rates in China, 1995-99. Lancet, 359, 835-840. doi:10.1016/S0140-6736(02)07954-0.

Phillips, M. R., Yang, G., Zhang, Y., Wang, L., Ji, H., \& Zhou, M. (2002). Risk factors for suicide in China: a national case-control psychological autopsy study. Lancet, 360, 1728-1736. doi:10.1016/S0140-6736(02)11681-3.

Pollock, L. R., \& Williams, J. M. G. (1998). Problem solving and suicide behavior. Suicide and Life-Threatening Behavior, 28(4), $375-387$. doi:10.1111/j.1943- 278X.1998.tb00973.x.

Preacher, K. J., \& Hayes, A. F. (2008). Asymptotic and resampling strategies for assessing and comparing indirect effects in multiple mediator models. Behavior Research Methods, 40, 879-891.

Qiu, L., \& Yan, B. (2009). Stressful life events, coping strategies, and mental health problems among Chinese vocational college students. Presented in the 3rd International Conference on Bioinformatics and Biomedical Engineering, ICBBE, 1-4, in June, Beijing. doi:10.1109/ICBBE.2009.5163430.

Roh, M. S., Jeon, H. J., Lee, H. W., Lee, H. J., Han, S. K., \& Hahm, B. J. (2007). Suicide-related behaviors among the college students. Journal of Korean Neuropsychiatry Association, 46, 35-40.

Sadowski, C., \& Kelley, M. L. (1993). Social problems solving in suicidal adolescents. Journal of Consulting and Clinical Psychology, 61(1), 121-127. doi:10.1037/ 0022-006X.61.1.121.

Schneider, B., \& Lee, Y. (1990). A model of academic success: the school and home environment of East Asian students. Anthropology and Education Quarterly, 21, 358-377. doi:10.1525/aeq.1990.21.4.04x0596x.

Speckens, A., \& Hawton, K. (2005). Social problem solving in adolescents with suicidal behavior: a systematic review. Suicide and Life-Threatening Behavior, 4, 365-387. doi:10.1521/suli.2005.35.4.365.

Stone, A. A., \& Neale, J. N. (1984). New measures of daily copping: development of and preliminary results. Journal of Personality and Social Psychology, 46, 892-906.

Sunnqvist, C.,Westrin, $\AA$, \& Träskman-Bendz, L. (2008). Suicide attempters: biological stressmarkers and adverse life events. European Archives of Psychiatry and Clinical Neuroscience, 258, 456-462. doi:10.1007/s00406-008-0819-6.

Thompson, R., Proctor, L. J., English, D. J., Dubowitz, H., Narasimhan, S., \& Everson, M. D. Suicidal ideation in adolescence: examining the role of recent adverse experiences. Journal of Adolescence, in press. doi:10.1016/j.adolescence.2011.03.003.

Toprak, S., Cetin, I., Guven, T., Can, G., \& Demircan, C. (2011). Self-harm, suicidal ideation, and suicide attempts among college students. Psychiatry Research, 187, 140-144. doi:10.1016/j.psychres.2010.09.009.

Uğurlu, N., \& Ona, N. (2009). Relationship between the stress-coping levels of university students and their probability of committing suicide. Social Behavior and Personality, 37(9), 1221-1230. doi:10.2224/sbp.37.9.1221.

Wadsworth, M. E., Gudmundsen, G. R., Raviv, T., Ahlkvist, J. A., McIntosh, D. N., Kline, G. H., et al. (2004). Coping with terrorism: age and gender differences in effortful and involuntary responses to September 11th. Applied Developmental Science, 8, $143-157$. doi:10.1207/s1532480xads0803_4.

Wadsworth, M. E., Raviv, T., Compas, B. E., \& Connor-Smith, J. K. (2005). Parent and adolescent responses to poverty-related stress: tests of mediated and moderated coping models. Journal of Child and Family Studies, 14(2), 283-298. doi:10.1007/s10826-005-5056-2.

Watson, D., Goldney, R., Fisher, L., \& Merritt, M. (2001). The measurement of suicidal ideation. Crisis: The Journal of Crisis Intervention and Suicide Prevention, 22(1), 12-14.

Wilson, K. G., Stelzer, J., Bergman, J. N., Kral, M. J., Inayatullah, M., \& Elliott, C. A. (1995). Problem solving, stress, and coping in adolescent suicide attempts. Suicide and Life-Threatening Behavior, 25(2), 241-252. doi:10.1111/j.1943-278X.1995.tb00923.x.

Xiao, J., \& Li, J. (1996). The investigation of the association between personality and coping. Chinese Journal of Behavioral Medical Science, 5(2), 79-81.

Xiao, J., \& Xu, X. (1996). Reliability and validity of the coping style questionnaire. Chinese Mental Health Journal, 10(4), 164-168.

Yang, B., \& Clum, G. A. (1994). Life stress, social support, and problem-solving skills predictive of depressive symptoms, hopelessness, and suicide ideation in an Asian student population: a test of a model. Suicide and Life-Threatening Behavior, 24(2), 127-139. doi:10.1111/j.1943-278X.1994.tb00797.x.

Zhang, J. (2010). Marriage and suicide among Chinese rural young women. Social Forces, 89(1), 311-326. doi:10.1353/sof.2010.0065.

Zhang, J., Gao, Q., \& Jia, C. (2011). Seasonality of Chinese rural young suicide and its correlates. Journal of Affective Disorders, 134, 356-364. doi:10.1016/j.jad. 2011.05.030.

Zhang, J., Jia, S., Jiang, C., \& Sun, J. (2006). Characteristics of Chinese suicide attempters: an emergency room study. Death Studies, 30(3), 259-268. doi:10. 1080/07481180500493443.

Zhang, J., \& Jin, S. (1996). Determinants of suicide ideation: a comparison of Chinese and American college students. Adolescence, 31(122), 451-467.

Zhang, K., Luo, J., Han, X., \& Ma, H. (1999). Suicide ideation and related factors in college freshmen. Chinese Mental Health Journal, 13(3), 144-145.

Zhang, J., Wieczorek, W. F., Conwell, Y., \& Tu, X. M. (2011). Psychological stains and youth suicide in rural China. Social Science and Medicine, 72, 2003-2010. doi:10.1016/j.socscimed.2011.03.048.

Zhang, J., Wieczorek, W. F., Conwell, Y., Tu, X. M., Wu, B., Xiao, S., \& Jia, C. (2010). Characteristics of young rural Chinese suicides: A psychological autopsy study. Psychological Medicine, 40, 581-589. doi:10.1017/S0033291709990808. 